\title{
The perceived value of mobile devices to passengers across the airline travel activity chain
}

\author{
Berendien Lubbe $^{\mathrm{a}, *}$, Liebie Louw ${ }^{\mathrm{b}}$ \\ a Department Tourism Management, University of Pretoria, Duxbury Road, Hatfield, Pretoria, Gauteng 0002, South Africa \\ ${ }^{\mathrm{b}}$ Department of Statistics, University of Pretoria, South Africa
}

Keywords:

Mobile technology

Travel activity chain

Mobile readiness

Perceived value

\begin{abstract}
A B S T R A C T
This paper investigates the determinants of air travellers 'readiness' to interface with airlines via mobile devices. A multi-dimensional measure is used based on factors influencing consumer adoption and use of mobile devices as well as perceptions of value across the air travel activity chain. The findings indicate that consumers' mobile readiness is directly related to their perception of the value of receiving information or making bookings on their mobile devices, but that certain predictors such as the purpose and frequency of travel and certain demographic characteristics are significant.
\end{abstract}

(c) 2009 Published by Elsevier Ltd.

\section{Introduction}

From a marketing perspective the greatest advantage of mobile communication and mobile commerce is that it offers suppliers a channel of direct communication with consumers via a mobile device at any time and at any place. Mobile devices create an opportunity to deliver new services to existing customers and to attract new ones. Airlines should see mobile communication and commerce as a new and more interactive way of doing business. "Rather than creating services based on experts' perception of usefulness and demand, developers should conduct regular market research to discover consumer needs and wants and transform the findings into services useful to consumers." (Kim et al., 2005). Mahatanankoon et al. (2005) articulate the importance to companies of understanding the elements and features of wireless electronic channels that are value-adding from the consumers' point of view as follows: "Every company entering the mobile space has the same goal - leveraging this channel to create customer value". The question of the extent to which consumers perceive value in, and are ready to interact via their mobile devices for airline-related communication and commerce arises. The problem for airlines is two-fold: First, they need to comprehend the essentials of what determines user "readiness" and second, airlines need to develop strategies on how to leverage mobile technology across the travel activity chain. The focus of this study is on the first problem: the readiness of consumers and what determines readiness in the airline environment. From the traveller perspective mobile

\footnotetext{
* Corresponding author. Tel.: +27 124204102; fax: +27 124203349 .

E-mail address: berendien.lubbe@up.ac.za (B. Lubbe).
}

interaction with the airline at any one, or all, of the points in the travel activity chain must be perceived to be of sufficient value to use mobile technology. The overall objective of the empirical research is to better understand the interrelationships between the perceived value of mobile communication and mobile commerce in the airline industry and to test consumers' "mobile readiness" across the airline travel activity chain.

\section{The concept of consumer "mobile readiness" and its application in the airline environment}

There has been little analysis on the airline industry regarding the application of mobile technology, and how customers perceive its value and significance. The adoption of $\mathrm{m}$-communication and $\mathrm{m}$-commerce by users has been the subject of a number of studies ranging from the identification of critical factors for adoption (Bruner and Kumar, 2005; Liljander et al., 2006; Wu and Wang, 2005), consumer perceptions of value (Mahatanankoon et al., 2005) to user satisfaction (Scharl et al., 2005). Sarker and Wells (2003) have added the dimension of perceived value and value maximisation. In the airline environment Park et al. (2004) define value as a customer's overall assessment of the utility of a product based on perceptions of what is received and what is given and service value has been identified as an important variable of customer satisfaction and behavioural intentions.

The value adoption model developed and tested by Kim et al. offers an understanding of the factors that influence value perceptions and how value perception leads to adoption from a value maximisation perspective. They found that there is a relationship between a customer's benefit and sacrifice-related beliefs and adoption intention. Perceived benefit is made up of two 
components: usefulness and enjoyment. Usefulness is defined as the value a user perceives when using the technology to serve his needs. Enjoyment refers to the extent to which the activity of using the technology is perceived to be enjoyable in its own right, apart from any performance consequences that may be anticipated, thus seen as an intrinsic benefit.

Perceived sacrifices are both monetary and non-monetary. Monetary spending includes the actual price of the product (the device) and the price of the communication/transaction. Nonmonetary costs usually include time, effort and other unsatisfactory spending related to technical factors. Studies such as that of Liljander et al. (2006) have also included dimensions of discomfort, insecurity, optimism and innovativeness as determinants of readiness. Mahatanankoon et al. stress the relevance of context and say that the creation of choice and new freedoms for customers within their location, situation and mission is the key value proposition of mobility. In this respect they raise the importance of why and when flexibility is valuable to customers since the benefits of this freedom are not equally valid for different mobile services and for different settings. Sarker and Wells confirm that different media are viewed as suitable for different objectives, given a social context. This is already illustrated in the airline industry where mobile phones, personal digital assistants and laptops are already used for searching and booking flights, altering flight arrangements, retrieving updated arrival and departure information, checking-in quickly and selecting seats (Hughes, 2004).

These examples of mobile applications in the airline industry reflect mobile interaction with customers at different segments of the travel activity chain. Buhalis (2003) says that where ICTs are used dynamically before, during and after the travel experience to serve passengers it reinforces the airline brand, particularly if they are "recognised" whenever they interface with the airline or its staff. For example, flight alerts through SMS, message pagers or email, as well as notification from either the airline or travel agency, can be sent when changes occurs mid-travel and new reservations must be made. Vouchers in the form of barcode SMS can be sent for meals or accommodation when flights are delayed. In-flight communications and constant interaction and customer service will also be crucial in the future. From an airline perspective Fig. 1 reflects the process of transforming a prospective customer into a loyal customer and represents all the segments in the customer travel activity chain at which mobile interaction can feasibly take place. From the traveller perspective mobile interaction with the airline at any one, or all, of the points in the travel activity chain must be perceived to be of sufficient value to use mobile technology. The focus here is on the user as a service consumer within the airline environment. It is evident that explanatory variables from personal demographics such as age and culture, personality traits that may reflect discomfort, insecurity, optimism and innovativeness, to technological self-efficacy, the perceived value (benefits and sacrifices as well as the usefulness) of various mobile applications to air travellers in their interaction with an airline across the travel activity chain, should be included in the model to test consumer mobile readiness. Thus it is hypothesised that, the readiness of air travellers to use their mobile devices for airlinerelated communication and commerce is positively related to its perceived value across the airline travel activity chain.

\section{Research design}

The overall purpose of the empirical research was to better understand the relationship between the use and perceived value of mobile communication and mobile commerce by air travellers across the travel activity chain. This relationship should illustrate the readiness of air travellers to communicate with airlines via their mobile devices. A multi-dimensional measure was adopted and in some areas adapted from the scales used by Mahatanankoon et al. and Kim et al. The questionnaire was used to determine types of mobile devices used, technology characteristics, features (mediums used for example text, voice), technological self-efficacy, level of confidence, perceived value (intrinsic and extrinsic), demographic characteristics, air travel profile (for example frequency of travel, purpose of travel) and readiness in the various stages of the airline activity chain. These questions using this multi-dimensional measure included 22 Likert scale statements which were each labelled on a five-point scale where; 1 is Strongly disagree, 2 is Disagree, 3 is Neither agree nor disagree, 4 is Agree and 5 is Strongly agree. The Likert scale statements adapted from Mahatanankoon et al. and Kim et al. were changed from a generalised mobileInternet perspective to a more specific perspective that focused on the airline industry.

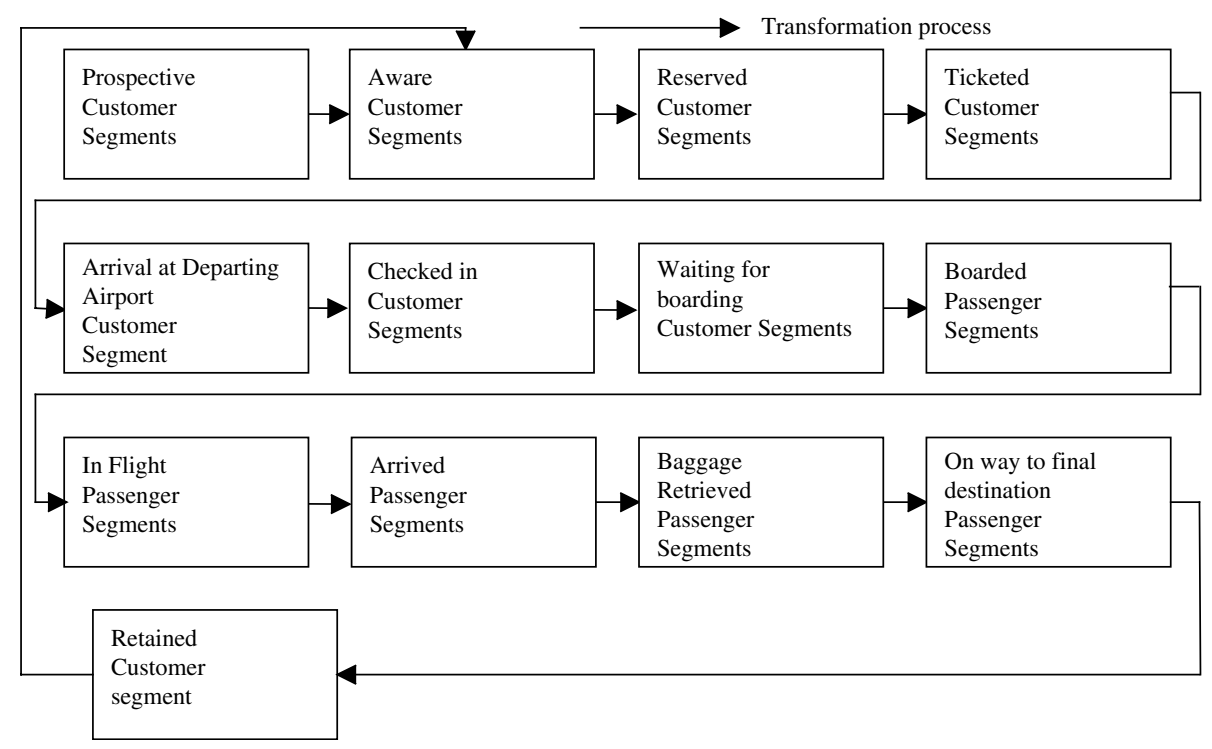

Fig. 1. The airline travel activity chain. Source: Vlok (2003). 
The target population consisted of air travellers travelling on two low-cost carriers in South Africa. A non-probability, convenience sampling method was used, with air travellers being targeted at the OR Tambo International Airport in Johannesburg and passengers on flights between Johannesburg and Cape Town during August and September of 2007. A final number of 327 usable questionnaires were generated. The respondents who participated in the study were of the ages 18 and older, male and female, travelling on two low-cost carriers in South Africa for either business or leisure purposes and owned a hand held device. The sample, however, was slightly dominated by male respondents (52\%) and the majority of the respondents fell into the 26 to 39-age-group which represented $32 \%$ of the sample. Fifty-four percent of the sample was English followed by the Afrikaans speaking respondents (34\%). Thirty-four reported a monthly income after tax of between R11000 and R30000, while $68 \%$ of respondents had a university degree or some form of higher qualification.

\section{Results}

Descriptive statistics were used to explore the data. Then exploratory factor analysis was performed to identify the underlying constructs, particularly with regard to the dependent variable readiness, and the independent variable perceived value across the airline travel activity chain. Analysis of variance was used to model relationships between the dependent variable "readiness" and the explanatory variables of perceived value of information and booking via mobile device, purpose and frequency of travel, qualifications, age and gender.

\subsection{Results of the exploratory factor analysis}

From the factor analysis two factors relating to perceived value in the airline environment were identified, the first reflecting the value of booking flights (Factor 1) and the second for receiving information from the airline via a mobile device (Factor 2). These are shown in Table 1. Factor analysis on value translates to the perceived benefits and usefulness of mobile devices to communicate with airlines across the airline activity chain with specific reference to the reliability, security, value for money and time efficiency of booking airline tickets (Factor 1). Similarly, value translates to the perceived benefits and usefulness of mobile devices for receiving information on flight schedule changes before and during the flight, for facilitating check-in and baggage collection as well as receiving information on future specials and promotions (Factor 2). A third factor "readiness" (Factor 3) could be identified from a number of variables which reflects consumer attitudes towards their mobile devices, as shown in Table 2. These attitudes represent consumers' intrinsic feelings towards their mobile devices, that is, what it represents to them, as well as their extrinsic usefulness and the motives for using it.

The mean score for Factor 1 is 3.34, for Factor 2 is 3.83, indicating that respondents perceive more value in receiving information via their mobile devices than they do in making bookings. Scores were expressed as a mean on a five-point scale where as before from 1 is for strongly disagree, etc.. On the readiness factor (Factor 3) respondents overall appear to be fairly neutral with a mean score of 3.38.

\subsection{Chi-square tests: relationship between readiness and respondents value perceptions}

The relationship between readiness and the perceived value of receiving information from the airline and the relationship between readiness and the perceived value of making bookings
Table 1

Factor loadings: Value.

\begin{tabular}{|c|c|c|c|}
\hline & & $\begin{array}{l}\text { Factor } 1 \\
\text { value (booking) }\end{array}$ & $\begin{array}{l}\text { Factor } 2 \text { value } \\
\text { (information) }\end{array}$ \\
\hline 14.5 & $\begin{array}{l}\text { Mobile devices are a reliable way to } \\
\text { book airline tickets }\end{array}$ & 0.980 & \\
\hline 14.4 & $\begin{array}{l}\text { Mobile devices are a secure way to book } \\
\text { airline tickets }\end{array}$ & 0.973 & \\
\hline 14.2 & $\begin{array}{l}\text { Booking airline tickets via a mobile } \\
\text { device offers value for money }\end{array}$ & 0.666 & \\
\hline 14.3 & $\begin{array}{l}\text { Compared to the time I need to put in, } \\
\text { the value of booking an airline ticket } \\
\text { with my mobile device makes it } \\
\text { worthwhile }\end{array}$ & 0.661 & \\
\hline 14.1 & $\begin{array}{l}\text { I plan to use mobile devices to book } \\
\text { airline tickets in the future }\end{array}$ & 0.650 & \\
\hline 15.2 & $\begin{array}{l}\text { I would like to receive information } \\
\text { relating to flight schedule changes and } \\
\text { delays before my flight via my mobile } \\
\text { device }\end{array}$ & & 0.832 \\
\hline 15.4 & $\begin{array}{l}\text { I would like to use my mobile device as } \\
\text { a means to facilitate check-in procedure } \\
\text { at airports }\end{array}$ & & 0.735 \\
\hline 15.3 & $\begin{array}{l}\text { I would like to receive information } \\
\text { relating to flight schedule changes and } \\
\text { delays during my flight via my mobile } \\
\text { device }\end{array}$ & & 0.721 \\
\hline 15.1 & $\begin{array}{l}\text { I would like to receive air travel } \\
\text { information alerts via my mobile device } \\
\text { regarding baggage collection }\end{array}$ & & 0.687 \\
\hline \multirow[t]{5}{*}{15.5} & $\begin{array}{l}\text { I would like to receive information from } \\
\text { airlines about future specials and } \\
\text { promotions via my mobile device }\end{array}$ & & 0.512 \\
\hline & $\%$ of the variance explained by the factor & $32.35 \%$ & $10.50 \%$ \\
\hline & Cronbach Alpha & 0.91 & 0.84 \\
\hline & Mean & 3.34 & 3.83 \\
\hline & Standard deviation & 0.85 & 0.83 \\
\hline
\end{tabular}

was tested using the Chi-square test. Highly significant relationships between mobile readiness and value perception in both information and booking via mobile device were found with a $p$-value of $<0.0001$ for the chi-square test in both cases.

A distinction was made between those flying for the purposes of leisure and those flying for the purposes of business with the latter group showing statistically significant trends in measuring the predictors of readiness. Further analysis focussed on those respondents travelling for business purposes. From the results it became necessary to further split the business traveller population into two distinct groups based on the number of times flown. The

Table 2

Factor loadings: Readiness.

\begin{tabular}{|c|c|c|}
\hline & & Factor 3 readiness \\
\hline 6.5 & $\begin{array}{l}\text { I like having the latest mobile device on the } \\
\text { market }\end{array}$ & 0.995 \\
\hline 6.6 & $\begin{array}{l}\text { I try to keep up to date with the latest } \\
\text { technology on the market }\end{array}$ & 0.883 \\
\hline 6.3 & $\begin{array}{l}\text { The mobile device that I use portrays an image } \\
\text { of who I am }\end{array}$ & 0.525 \\
\hline 6.1 & $\begin{array}{l}\text { I would use my mobile device more often if it } \\
\text { had more features }\end{array}$ & 0.465 \\
\hline 6.2 & $\begin{array}{l}\text { My mobile device forms an important part of } \\
\text { my every day life }\end{array}$ & 0.369 \\
\hline \multirow[t]{5}{*}{6.4} & $\begin{array}{l}\text { It saves me time when I use my mobile device } \\
\text { whilst waiting in a traffic jam, in a queue or at } \\
\text { the airport }\end{array}$ & 0.337 \\
\hline & $\%$ of the variance explained by the factor & $11.12 \%$ \\
\hline & Cronbach Alpha & 0.79 \\
\hline & Mean & 3.38 \\
\hline & Standard deviation & 0.81 \\
\hline
\end{tabular}


Table 3

Readiness - Category 1 traveller.

\begin{tabular}{|c|c|c|}
\hline \multirow{2}{*}{$\frac{\text { Dependent variable }}{\text { Independent variable: }}$} & \multicolumn{2}{|c|}{ Readiness } \\
\hline & Mean & $p$-value \\
\hline Qualification & & 0.0068 \\
\hline Secondary level & 3.76 & \\
\hline Tertiary level & 3.45 & \\
\hline Perceived value (information) & & 0.0109 \\
\hline Agree & 3.64 & \\
\hline Not agree & 3.19 & \\
\hline Perceived value (booking) & & $<0.0001$ \\
\hline Agree & 3.80 & \\
\hline Not agree & 3.11 & \\
\hline
\end{tabular}

results also showed that a significant relationship between mobile readiness and frequency of travel exists with a $p$-value of 0.0106 for the chi-square test, indicating that two different models for predicting readiness had to be built for two business travel groups based on frequency of travel. The first group (Category 1 travellers) flew 3 or more times during the past 12 months and the second group (Category 2 travellers) flew less than 3 times during the past 12 months.

4.3. Analysis of variance models: relationships between readiness and respondents value perceptions, demographic and behavioural characteristics

The first model built represents the READINESS of the Category 1 traveller. Significant predictors for model 1 were found to be QUALIFICATION, PERCEIVED VALUE (information) and PERCEIVED VALUE (booking), shown in Table 3.

The second model represents the Category 2 traveller. Significant predictors for model 2 were found to be an interaction between AGE and QUALIFICATION and an interaction between GENDER and PERCEIVED VALUE (booking), and PERCEIVED VALUE (booking), and PERCEIVED VALUE (information), shown in Table 4.

These models are both significant with $p$-values of the respective $F$-tests $<0.0001$.

The overall results thus show a significant relationship between mobile readiness and perceived value, indicating that the readiness of air travellers to use their mobile devices for airline-related communication and commerce is positively related to its perceived value across the airline travel activity chain. The results also show that readiness is not only dependent on the perceived value of receiving airline information and doing bookings but is also related to the purpose and frequency of travel.

Contrary to expectation, amongst the more travelled respondents, the less qualified exhibit a greater "mobile readiness", contradicting a certain logic that the lower the qualification of the respondent, the less confident or positive he or she would be in terms of using a mobile device in the airline environment. It could be argued that these respondents may have higher expectations, and are perhaps in a sense more adventurous than the more highly qualified on using the mobile device for airline-related communication. The reason that the more highly qualified respondents and more frequent traveller, exhibit less "mobile readiness" could arguably be ascribed to them being more critical of what they
Table 4

Readiness - Category 2 traveller.

\begin{tabular}{|c|c|c|}
\hline \multirow{2}{*}{$\frac{\text { Dependent variable }}{\text { Independent variable: }}$} & \multicolumn{2}{|c|}{ Readiness } \\
\hline & Mean & $p$-value \\
\hline Age/qualification & & 0.0141 \\
\hline$<40 /$ Secondary & 3.80 & \\
\hline$<40 /$ Tertiary & 3.14 & \\
\hline$\geq 40 /$ Secondary & 3.18 & \\
\hline$\geq 40 /$ Tertiary & 3.21 & \\
\hline Gender/perceived value (booking) & & 0.0171 \\
\hline Male Agree & 3.72 & \\
\hline Male Not agree & 2.801 & \\
\hline Female Agree & 3.34 & \\
\hline Female Not agree & 2.93 & \\
\hline Perceived value (booking) & & $<0.0001$ \\
\hline Agree & 3.52 & \\
\hline Not agree & 2.88 & \\
\hline Perceived value (information) & & 0.0061 \\
\hline Agree & 3.38 & \\
\hline Not agree & 2.82 & \\
\hline
\end{tabular}

perceive the value of receiving airline information via their mobile devices is.

For the less frequent traveller, two further determinants of mobile readiness emerge, gender as well as age in interaction with qualification, displays a significant impact on mobile readiness. The younger less qualified respondents show a significantly higher mobile readiness than the younger more highly qualified as well as the older less qualified and older more highly qualified respondents. Again this result may be attributed to an expectation or adventurousness by the younger less qualified respondents on using the mobile device for airline-related information. The survey also showed that in this group, females tend to be less mobile ready than males. Those that perceive less value in receiving airlinerelated information also exhibit a significantly less positive attitude towards using the mobile device for this purpose.

\section{References}

Bruner II, G.C., Kumar, A., 2005. Explaining consumer acceptance of handheld internet devices. Journal of Business Research 58, 553-558.

Buhalis, D., 2003. eTourism: Information Technology for Strategic Tourism Management. Pearson Education Limited, London.

Hughes, D., 2004. Back to the future. Aviation Week and Space Technology 161, 74-75.

Kim, H., Chan, C.H., Gupta, S., 2005. Value-based adoption of mobile internet: an empirical investigation. Decision Support Systems 43, 111-126.

Liljander, V., Gillberg, F., Gummerus, J., van Riel, A., 2006. Technology readiness and the evaluation and adoption of self-service technologies. Journal of Retailing and Consumer Services 13, 177-191.

Mahatanankoon, P., Wen, H.J., Lim, B., 2005. Consumer-based m-commerce: exploring consumer perception of mobile applications. Computer Standards and Interfaces 27, 347-357.

Park, J., Robertson, R., Wu, C., 2004. The effect of airline service quality on passengers' behavioral intentions: a Korean case study. Journal of Air Transport Management 10, 435-439.

Sarker, S., Wells, J.D., 2003. Understanding mobile handheld device use and adoption. Communications of the ACM 46, 35-39.

Scharl, A., Dickinger, A., Murphy, J., 2005. Diffusion and success factors of mobile marketing. Electronic Commerce Research and Applications 4, 159-173.

Vlok, N., 2003. Airline Distribution. Presentation at University of Pretoria, 7 August 2003.

Wu, J., Wang, S., 2005. What drives mobile commerce? An empirical evaluation of the revised technology acceptance model. Information and Management 42 , 719-729. 